\title{
Situs Inversus Totalis
}

\author{
Julie Huss-Bawab, Linda J. Szymanski
}

Acad Forensic Pathol. 2018 8(4): 957-963

\section{AUTHORS \\ Julie Huss-Bawab MD, Los Angeles County Department of Medical Examiner-Coroner}

Roles: Project conception and/or design, data acquisition, analysis and/or interpretation, manuscript creation and/or revision, approved final version for publication, accountable for all aspects of the work, principal investigator of the current study.

Linda J. Szymanski DO, Los Angeles County Department of Medical Examiner-Coroner

Roles: Project conception and/or design, data acquisition, analysis and/or interpretation, manuscript creation and/or revision, approved final version for publication, accountable for all aspects of the work, principal investigator of the current study.

CORRESPONDENCE

Linda J. Szymanski DO, 1104 N. Mission Road, Los Angeles CA 90033, LSzymanski@coroner.lacounty.gov

ETHICAL APPROVAL

As per Journal Policies, ethical approval was not required for this manuscript

STATEMENT OF HUMAN AND ANIMAL RIGHTS

This article does not contain any studies conducted with animals or on living human subjects

STATEMENT OF INFORMED CONSENT

No identifiable personal data were presented in this manuscript

DISCLOSURES \& DECLARATION OF CONFLICTS OF INTEREST

The authors, reviewers, editors, and publication staff do not report any relevant conflicts of interest

FINANCIAL DISCLOSURE

The authors have indicated that they do not have financial relationships to disclose that are relevant to this manuscript

KEYWORDS

Forensic pathology, Situs inversus totalis

INFORMATION

ACADEMIC FORENSIC PATHOLOGY: THE OFFICIAL PUBLICATION OF THE NATIONAL ASSOCIATION OF MEDICAL EXAMINERS

(02018 Academic Forensic Pathology International • (ISSN: 1925-3621) • https://doi.org/10.1177/1925362118821495

Submitted for consideration on 23 Jul 2018. Accepted for publication on 9 Oct 2018 
Internal organ development of the embryo is asymmetric, with the normal left and right sides of the body being different in form (1). The "normal" orientation of the heart and viscera is referred to as situs solitus. Changes in normal laterality can range from mirror image situs inversus totalis, to varying degrees of partial changes referred to collectively as situs ambiguous $(1,2)$. The severity of the congenital malformation is often categorized based upon the prevalence of associated anomalies, which can include complex congenital heart defects (3).

A 21-year-old gravida two para one $\left(\mathrm{G}_{2} \mathrm{P}_{1}\right)$ woman at 33 weeks gestation presented to the hospital for premature delivery. Her prior pregnancy was uneventful, though it had been deemed "high risk" due to a low lying placenta. She had been seen three months prior for decreased fetal movements at which time an ultrasound examination confirmed fetal heart tones. She admitted to use of acetaminophen and hydrocodone during the pregnancy for gallstone and dental issues.

A baby boy was delivered within the ambulance en route to the hospital, with initial Apgar scores of 5 and 5 with no spontaneous movements or respirations. A whole baby radiograph of the newborn revealed situs inversus. Due to difficulty with intubation, the baby was transferred to a tertiary hospital for advanced care. An echocardiogram revealed poor cardiac motion and a subsequent whole body radiograph revealed a pneumoperitoneum. The baby continued to deteriorate and despite advance cardiovascular life support, the baby died at approximately six hours of life.

At autopsy, external examination revealed dysmorphic features including low-set ears with slight posterior rotation, retrognathia, and a triangular facies (Image 1). There was marked edema of the hands and feet with anasarca confirmed on internal examination with peritoneal pleural effusions.

Internal examination confirmed the diagnoses of situs inversus totalis. The most striking features included the apex of the heart pointing toward the right, the stomach originating on the right and extending toward the duodenum on the left, and the spleen present in the right upper quadrant of the abdomen (Images 2 to 4). There was pulmonary hypoplasia, with the combined weight of $8.7 \mathrm{~g}$, far lighter than the $31.8+13.5 \mathrm{~g}$ expected for gestational age. No congenital cardiac anomalies were present. The cause of death was determined to be multiple congenital anomalies, with prematurity and intrauterine opioid exposure as contributing conditions.

Laterality defects, which include situs inversus totalis, have an estimated birth prevalence of 1.1 per 10000 live births, based on the data collected in the National Birth Defects Prevalence Study (3). Cases were associated with preterm delivery, maternal age under 20 years, and non-white maternal race (3). A recently published meta-analysis and review of the literature found that up to one quarter of fetuses with heterotaxia died during or after surgery (4). Congenital anomalies of the biliary tract, complex cardiac congenital defects, and intestinal malrotation were most often found. A major determinate of poor perinatal outcome was hydrops fetalis (4).

A retrospective study by McGovern et al. found that patients with heterotaxia had a worse prognosis, even when similar underlying cardiac abnormalities were identified (5). Additionally, the study found no statistically significant survival outcomes associated with perinatal diagnosis or any statistically significant cardiac anomalies associated with outcomes (5).

The type of cardiac anomalies varied by underlying laterality defect. Complex cardiac congenital defects, including double outlet right ventricle, atrioventricular canal defects, pulmonary stenosis, non-tetralogy of Fallot pulmonary atresia with ventricular septal defect, and totally and partially anomalous pulmonary venous return were more commonly associated with heterotaxy anomalies, while situs inversus totalis is more commonly associated with Dandy-Walker malformation, anotia/microtia, and limb deficiency (3).

The cause of laterality disorders has been explored for over two decades, with a consensus that their etiology is multifactorial with genetic and environmental contributions $(6,7)$. The development of laterality disor- 


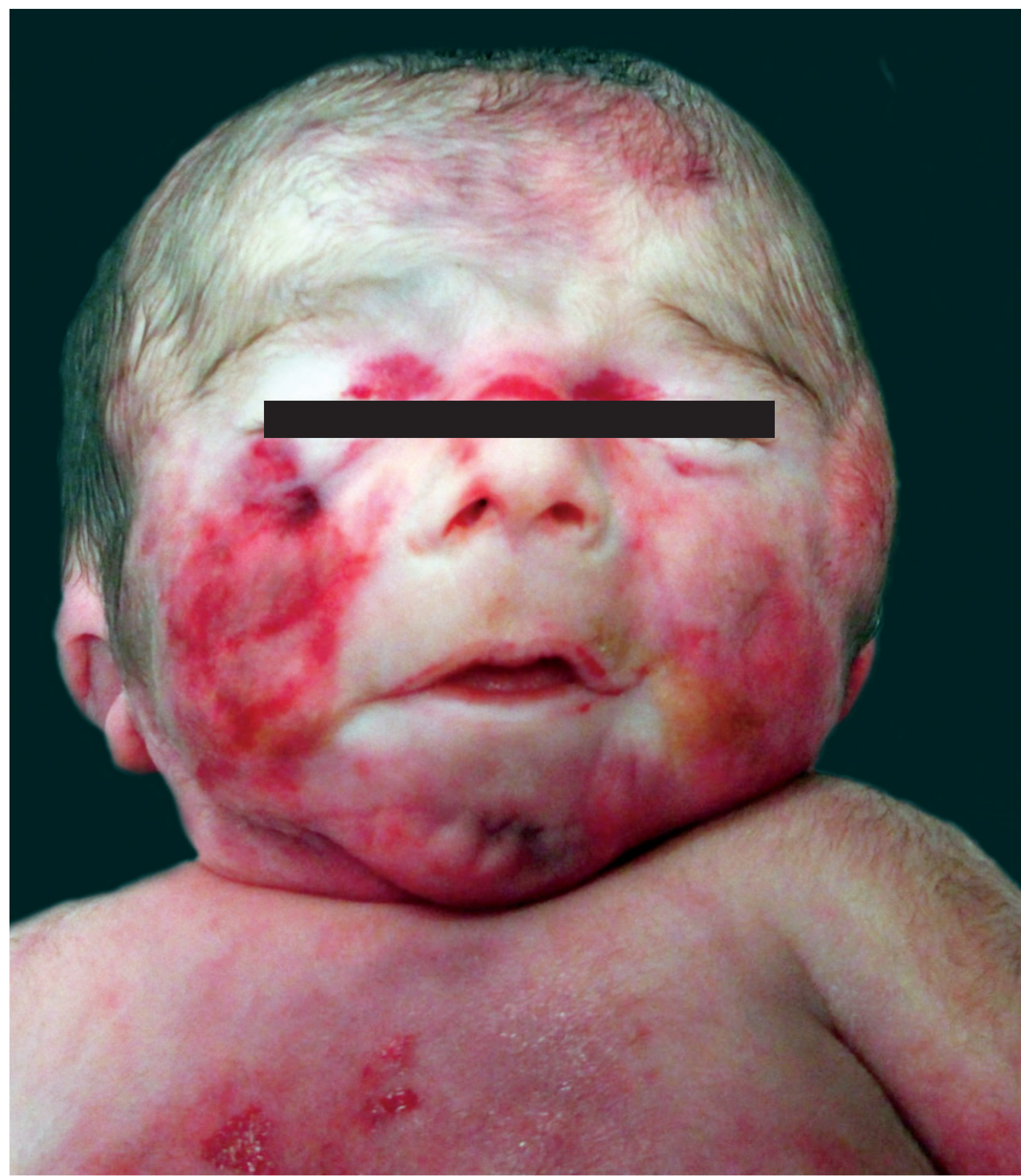

Image 1: Examination of the face revealed dysmorphic features including low-set ears with slight posterior rotation, retrognathia, and a triangular facies.

\section{Page 959}

Huss-Bawab \& Szymanski • Situs Inversus Totalis

ACADEMIC FORENSIC PATHOLOGY: THE OFFICIAL PUBLICATION OF THE NATIONAL ASSOCIATION OF MEDICAL EXAMINERS

(C2018 Academic Forensic Pathology International

Downloaded from www.afpjournal.com by an AFP Journal subscriber

This article is for personal use only and may not be shared or distributed in any fashion 


\section{IMAGES IN FORENSIC PATHOLOGY}

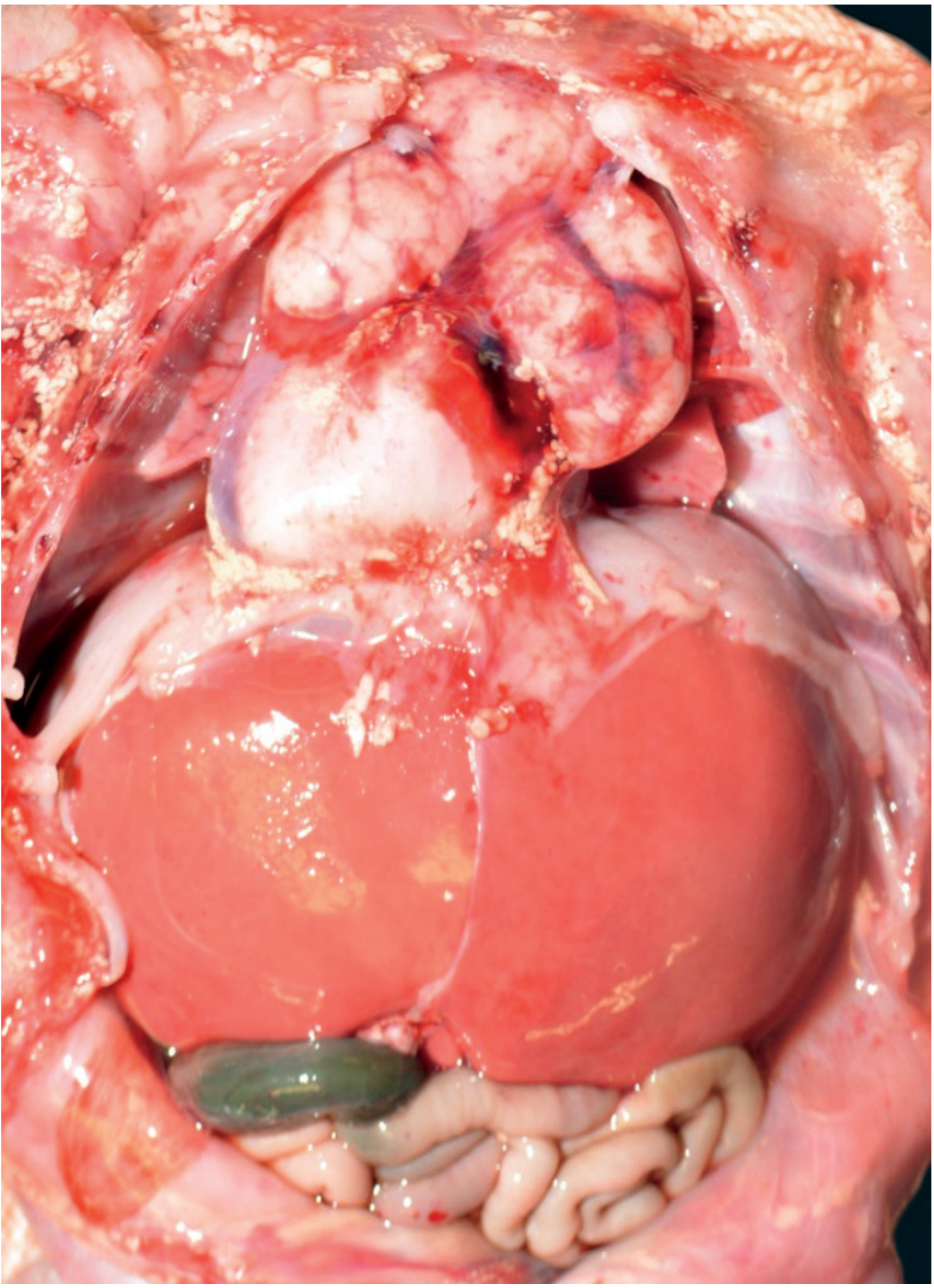

Image 2: In situ examination demonstrated dextrocardia with the apex of the heart located on the right side and the large lobe of the liver on left side.

\section{Page 960}

Huss-Bawab \& Szymanski • Situs Inversus Totalis

ACADEMIC FORENSIC PATHOLOGY: THE OFFICIAL PUBLICATION OF THE NATIONAL ASSOCIATION OF MEDICAL EXAMINERS

(C2018 Academic Forensic Pathology International

Downloaded from www.afpjournal.com by an AFP Journal subscriber

This article is for personal use only and may not be shared or distributed in any fashion 


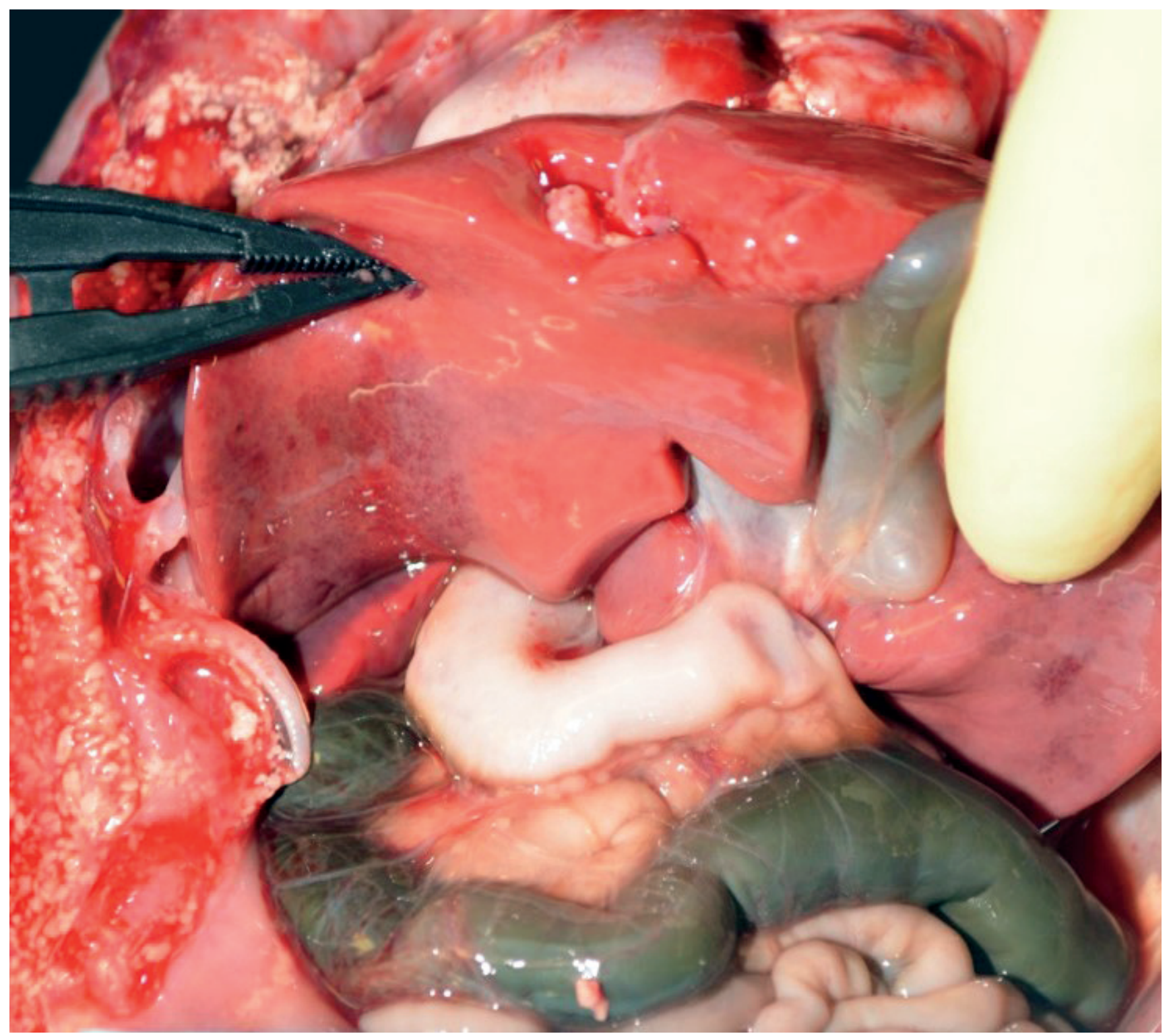

Image 3: Reflection of the liver revealed a right-sided stomach and duodenum.

ders has been associated with ciliary abnormalities, or ciliopathies, as well as genes identified as playing roles in laterality development, such as NODAL and PITX2 $(6,7)$. The extent of involvement of environmental factors is less known (7); however, studies have found associations with certain teratogenic drugs, including prenatal drug exposure to follitropin-alfa and drugs used in nicotine exposure (8).
While laterality disorders like situs inversus totalis are rare, it is important to be able to recognize features of heterotaxia and understand their connection with other critical congenital anomalies that can explain the cause of death. 


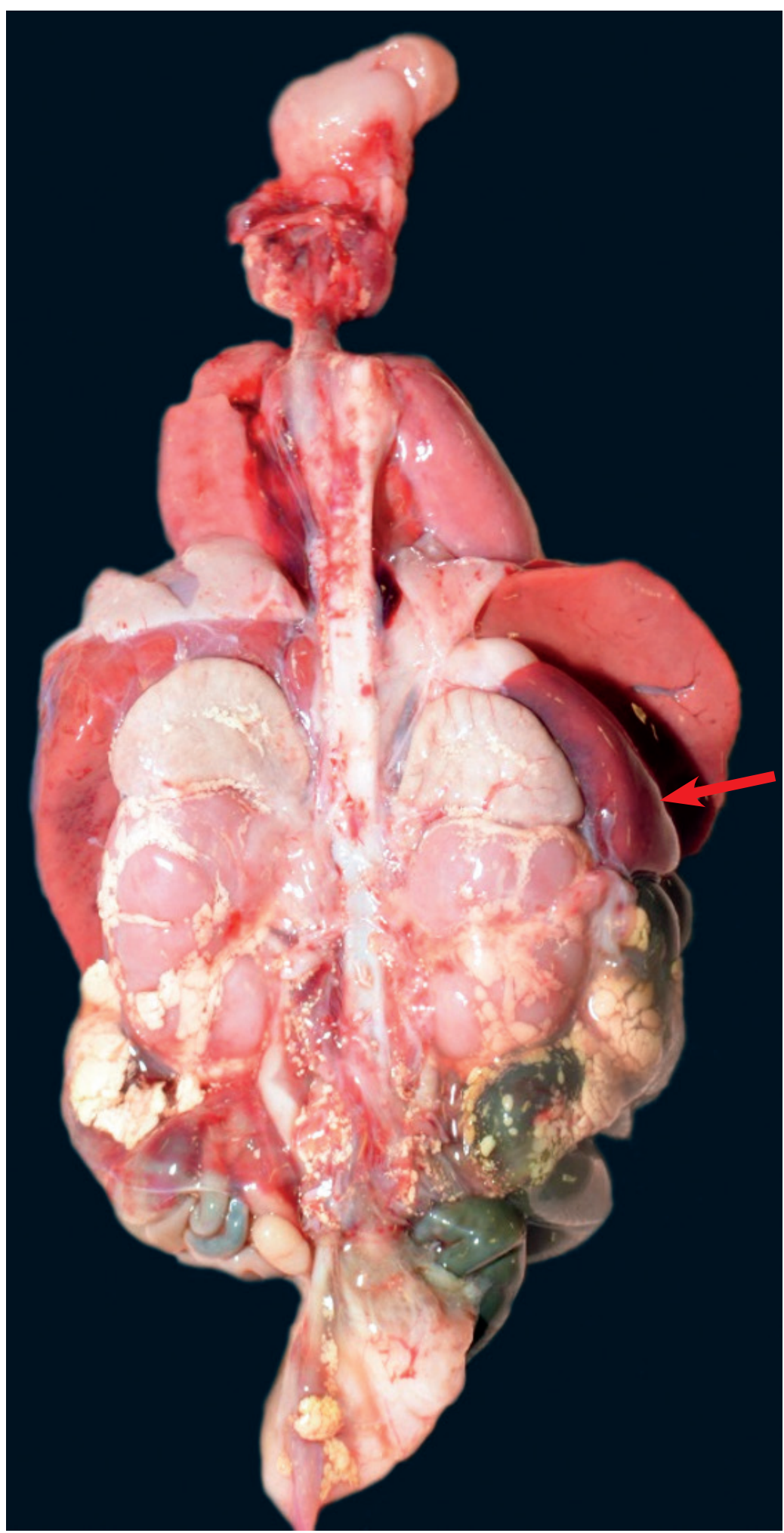

Image 4: Pulmonary hypoplasia and right-sided spleen (arrow) is best seen on the posterior view of en bloc specimen.

\section{Page 962}

Huss-Bawab \& Szymanski • Situs Inversus Totalis

ACADEMIC FORENSIC PATHOLOGY: THE OFFICIAL PUBLICATION OF THE NATIONAL ASSOCIATION OF MEDICAL EXAMINERS

(C2018 Academic Forensic Pathology International

Downloaded from www.afpjournal.com by an AFP Journal subscriber

This article is for personal use only and may not be shared or distributed in any fashion 


\section{REFERENCES}

1) Lambert TE, Kuller J, Small M, et al. Abnormalities of fetal situs: an overview and literature review. Obstet Gynecol Surv. $2016 \mathrm{Jan}$; 71(1): 33-8. PMID: 26819133. https://doi.org/10.1097/OGX.0000000000000262.

2) Degenhardt K, Rychik J. Fetal situs, isomerism, heterotaxy syndrome: diagnostic evaluation and implication for postnatal management. Curr Treat Options Cardiovasc Med. 2016 Dec; 18(12):77. PMID: 27844411. https://doi.org/10.1007/s11936-016-0494-2.

3) Lin AE, Krikov S, Riehle-Colarusso T, et al. Laterality defects in the national birth defects prevention study (1998-2007): birth prevalence and descriptive epidemiology. Am J Med Genet A. 2014 Oct; 164A(10):2581-91. PMID: 25099286. PMCID: PMC4462240. https://doi.org/10.1002/ajmg.a.36695.

4) Buca DIP, Khalil A, Rizzo G, et al. Outcome of prenatally diagnosed fetal heterotaxy: systematic review and meta-analysis. Ultrasound Obstet Gynecol. 2018 Mar; 51(3):323-330. PMID: 28603940. https://doi.org/10.1002/uog.17546.
5) McGovern E, Kelleher E, Potts JE, et al. Predictors of poor outcome among children with heterotaxy syndrome: a retrospective review. Open Heart. 2016 Oct 11;3(2):e000328.

PMID: 27843561. PMCID: PMC5073560. https://doi.org/10.1136/openhrt-2015-000328.

6) Pennekamp P, Menchen T, Dworniczak B, Hamada H. Situs inversus and ciliary abnormalities: 20 years later, what is the connection? Cilia. 2015 Jan 14; 4(1):1. PMID: 25589952. PMCID: PMC4292827. https://doi.org/10.1186/s13630-014-0010-9.

7) Catana A, Apostu AP. The determination factors of left-right asymmetry disorders- a short review. Clujul Med. 2017; 90(2):139-46. PMID: 28559696. PMCID: PMC5433564. https://doi.org/10.15386/cjmed-701.

8) van Veenendaal NR, Kusters CD, Oostra RJ, et al. When the right (drug) should be left: prenatal drug exposure and heterotaxy syndrome. Birth Defects Res A Clin Mol Teratol. 2016 Jul; 106(7):573-9. PMID: 26991659. https://doi.org/10.1002/bdra.23497. 